\title{
Editorial
}

\section{Control of Nosocomial Methicillin-Resistant Staphylococcus aureus: Where Shall We Send Our Hospital Director Next Time?}

\author{
Stephan Harbarth, MD, MS; Didier Pittet, MD, MS
}

\begin{abstract}
All I maintain is that on this earth there are pestilences and there are victims, and it is up to us, so far as possible, not to join forces with the pestilences.-Albert Camus ${ }^{1}$
\end{abstract}

In the midst of a hospital-wide campaign to combat the rising incidence of methicillin-resistant Staphylococcus aureus (MRSA) at our institution, our hospital director, together with other high-ranking hospital administrators, traveled to Boston, Massachusetts, to visit a prestigious teaching hospital and learn more about the way health care is being delivered in the United States. Apparently, our director was impressed by the efficiency and quality of healthcare delivery he encountered. Moreover, after returning to Geneva, he informed senior staff members that hospital officials in Boston had told him that their hospital no longer applied isolation precautions to control the spread of MRSA, 35 years after the first description of a hospital-wide MRSA outbreak in that city. ${ }^{2}$ At the same time, we knew that we had had more than 700 new MRSA cases in our hospital in 2002 and that substantial efforts would be necessary to stop the spread of MRSA. Those who are facing endemic MRSA infections may ask themselves whether the hospital in Boston is really the kind of role model we want to follow in the 21st century. Is it time to give up fighting and searching for MRSA ${ }^{3}$ Is the "war" over?4 Or, alternatively, should we not be considering increased efforts to control this persistent pathogen with screening policies and isolation precautions?

Endemic MRSA cross-infection represents a global problem, although major differences in MRSA control have been achieved with different strategies. ${ }^{5.7} \mathrm{~A}$ few countries such as Finland and the Netherlands have managed to control MRSA to a low level using active surveillance cultures and contact precautions. ${ }^{8,9}$ Other countries (eg, Canada and Germany) that were "MRSA naive" until recently have not installed stringent, nationwide MRSA surveillance and control measures and are now in the middle of some large MRSA epidemics. ${ }^{10-12}$ Some countries with high prevalences (eg, Belgium and France) have managed to stabilize the situation in confined geographic areas. For instance, in a large set of teaching hospitals in the Paris area (Assistance Publique-Hôpitaux de Paris; 25,000 beds) where a stringent program for MRSA control was set up in 1993, the proportion of MRSA among clinical isolates of $S$. aureus decreased between 1993 and 2002 from 55\% to 25\% in patients in the intensive care unit and overall from $39 \%$ to $29 \%$ in patients in the acute care unit (V. Jarlier, MD, personal communication, April 16, 2003). Yet, few countries such as Japan have simply ignored this public health problem for more than three decades.

Perhaps second only to Japan, the United States has the unenviable position of being one of the world leaders in the prevalence of methicillin resistance and of reduced susceptibility to glycopeptides among $S$. aureus isolates. ${ }^{6,13,14}$ For instance, more than $50 \%$ of all S. aureus isolates in U.S. intensive care units are now methicillin resistant and, recently, the first high-level vancomycin-resistant $S$. aureus isolates were reported from the United States. ${ }^{13,15}$ This worrisome finding suggests that previous initiatives to stop the spread of multidrug-resistant $S$. aureus in the United States have failed. In this context, it is surprising to read the following statement from U.S. public health authorities (unsubstantiated by data) on a frequently visited web site: "Standard Precautions, as described in the 'Guideline for Isolation Precautions in Hospitals," 16 should control the spread of MRSA in most instances." ${ }^{17}$ To our understand- 
ing, standard precautions have been required by federal regulation for 7 years in all U.S. healthcare facilities but this does not seem to have resulted in control of the problem. One carefully performed study showed that MRSA transmission occurred 16 times more often with standard precautions than when colonized patients were identified with surveillance cultures and cared for using contact precautions. ${ }^{18}$ Another recent study from the Netherlands suggested an even higher relative risk for spread when patients were cared for using standard precautions as compared with isolation precautions. ${ }^{19}$ Indeed, many reports have stressed the importance of active screening policies and contact isolation for MRSA-positive patients, especially in high-risk units. ${ }^{20.21}$

In this issue of Infection Control and Hospital Epidemiology, Saiman et al. ${ }^{22}$ report the containment of a MRSA outbreak in a neonatal intensive care unit in which screening cultures, contact isolation, and cohorting of neonates and healthcare workers were being successfully used. By contrast, an adult intensive care unit in Australia used only standard precautions and had a high rate of MRSA transmission, as shown by regular admission and discharge screening. ${ }^{23}$ The difference in outcome between the two units is striking and one is tempted to implicate the differing control strategies.

The conclusions of these two articles support the recommendations of a new guideline also published in this issue of Infection Control and Hospital Epidemiology regarding the control of nosocomial spread of MRSA and vancomycin-resistant enterococci (VRE) ${ }^{24}$ In this guideline, Muto et al. recommend that hospitals in the United States and elsewhere implement surveillance cultures and contact precautions to control cross-infection of multidrug-resistant gram-positive cocci. Indeed, previous guidelines have failed to contain MRSA, which has continued to increase dramatically despite their use. ${ }^{25}$ The new guideline considers this fact, extensively reviews the relevant literature, covers many areas of uncertainty, and provides a sound framework for MRSA and VRE control in the future. It represents a robust and well-documented summary of the available evidence. Therefore, we welcome and commend this guideline.

A limitation in the management and prevention of nosocomial infections has been the lack of evidence from randomized trials. Recent work on a variety of topics makes this clear. For example, the authors of a recent guideline on the management of catheter-related infections noted that randomized trials were unavailable for most of the areas covered. ${ }^{26}$ Likewise, the recently published hand hygiene guideline emphasized the need for the use of alcohol hand rubs despite the absence of any randomized trials showing that this would reduce infection rates..$^{27}$ Perhaps in part due to the lack of such studies, widespread misconceptions about the value of alcohol-based hand antisepsis persisted through the 20 th century. ${ }^{28}$ Nevertheless, the conclusions and recommendations of both of these guidelines appear reasonable. For many important questions regarding infection control and MRSA control in particular, we may never obtain data from randomized trials because of the general lack of funding, feasibility issues, and ethical dilemmas. Thus, the opinions of experts critically appraising the available epidemiologic evidence that supports infection control practices will likely always remain a key component of guidelines in our field.

We consider the conclusions of the guideline for preventing nosocomial spread of MRSA and VRE to be well reasoned and correct based on the available data. If all public health authorities were to adopt this guideline and all healthcare facilities were to follow its proactive approach, it is likely that the almost universal failure to control MRSA in U.S. healthcare facilities would be reversed. It might be argued that some of the studies, such as that by Saiman et al. in this issue, used additional measures such as cohorting or an isolation ward. However, many of the studies reporting successful control did not use these two measures and virtually all did report using active surveillance cultures and contact precautions, which seem to be almost a sine qua non for success. Studies reporting successful control without these measures seem to be the exception rather than the rule, and the success reported in such studies has often been modest. ${ }^{29}$

We feel certain that those who have not read the many studies referenced by the new guideline will be tempted to criticize its bold proposal that all healthcare facilities start controlling MRSA and VRE infections. Whatever the criticism, health authorities and hospital epidemiologists are well advised to put teeth and money into their control efforts as recommended by the guideline. Hospital administrators in particular should not wait until nosocomial acquisition rates of MRSA become a key quality indicator for hospital benchmarking. ${ }^{5,30}$ Clearly, MRSA control is cost-effective, and particularly so in high-risk units. ${ }^{20,31,32} \mathrm{We}$, like others, are convinced that there is no level of MRSA prevalence for which active control measures are not warranted. Precautions to combat transmission of multidrug-resistant microorganisms such as MRSA and VRE on a routine basis should find their way into all hospitals with the ultimate benefit of improving patient safety.

\section{REFERENCES}

1. Camus A. The Plague. New York: Vintage Books; 1972

2. Barrett FF, McGehee RF, Finland M. Methicillin-resistant Staphylococcus aureus at Boston City Hospital. $N$ Engl J Med 1968:279:441-448.

3. Teare EL, Barrett SP. Is it time to stop searching for MRSA? Stop the ritual of tracing colonised people. BMJ 1997;314:665-666.

4. Farrington M, Redpath C, Trundle C, Coomber S, Brown NM. Winning the battle but losing the war: methicillin-resistant Staphylococcus aureus infection at a teaching hospital. QJM 1998;91:539-548.

5. Harbarth S, Pittet D. MRSA: a European currency of infection control. QJM 1998;91:519-521.

6. Diekema DJ, Pfaller MA, Schmitz FJ, et al. Survey of infections due to Staphylococcus species: frequency of occurrence and antimicrobial susceptibility of isolates collected in the United States, Canada, Latin America, Europe, and the Western Pacific region for the SENTRY Antimicrobial Surveillance Program, 1997-1999. Clin Infect Dis 2001;32 (suppl 2):S114-S132.

7. Harbarth S, Albrich W, Goldmann DA, Huebner J. Control of multiply resistant cocci: do international comparisons help? Lancet Infect Dis 2001;1:251-261.

8. Vriens M, Blok H, Fluit A, Troelstra A, Van Der Werken C, Verhoef J. 
Costs associated with a strict policy to eradicate methicillin-resistant Staphylococcus aureus in a Dutch University Medical Center: a 10-year survey. Eur J Clin Microbiol Infect Dis 2002;21:782-786.

9. Kotilainen P, Routamaa M, Peltonen R, et al. Elimination of epidemic methicillin-resistant Staphylococcus aureus from a university hospital and district institutions, Finland. Emerg Infect Dis 2003;9:169-175.

10. Simor AE, Ofner-Agostini M, Bryce E, et al. The evolution of methicillinresistant Staphylococcus aureus in Canadian hospitals: 5 years of national surveillance. CMAJ 2001;165:21-26.

11. Afif W, Huor P, Brassard P, Loo VG. Compliance with methicillin-resistant Staphylococcus aureus precautions in a teaching hospital. Am J Infect Control 2002;30:430-433.

12. Gastmeier P, Geffers C, Sohr D, Schwab F, Behnke M, Ruden H. Surveillance of nosocomial infections in intensive care units: current data and interpretations. Wien Klin Wochenschr 2003;115:99-103.

13. National Nosocomial Infections Surveillance (NNIS) System report: data summary from January 1992 to June 2002, issued August 2002. Am I Infect Control 2002;30:458-475.

14. Tenover FC, Biddle JW, Lancaster MV. Increasing resistance to vancomycin and other glycopeptides in Staphylococcus aureus. Emerg Infect Dis 2001;7:327-332.

15. Centers for Disease Control and Prevention. Staphylococcus aureus resistant to vancomycin: United States, 2002. JAMA 2002;288:824-825.

16. Garner JS. Guideline for isolation precautions in hospitals: the Hospital Infection Control Practices Advisory Committee. Infect Control Hosp Epidemiol 1996;17:53-80.

17. Centers for Disease Control and Prevention. MRSA: Information for Health Care Personnel. Atlanta, GA: Centers for Disease Control and Prevention. Available at www.cdc.gov/ncidod/hip/ARESIST/mrsahcw.htm. Accessed March 5, 2003

18. Jernigan JA, Titus MG, Gröschel DHM, Getchell-White SI, Farr BM. Effectiveness of contact isolation during a hospital outbreak of methicillin-resistant Staphylococcus aureus. Am J Epidemiol 1996;143:496-504.

19. Vriens MR, Fluit AC, Troelstra A, Verhoef J, Van Der Werken C. Are MRSA more contagious than MSSA in a surgical intensive care unit? Infect Control Hosp Epidemiol 2002;23:491-494.

20. Rubinovitch B, Pittet D. Screening for methicillin-resistant Staphylococcus aureus in the endemic hospital: what have we learned? J Hosp Infect 2001;47:9-18.

21. Lucet JC, Chevret S, Durand-Zaleski I, Chastang C, Regnier B.
Prevalence and risk factors for carriage of methicillin-resistant Staphylococcus aureus at admission to the intensive care unit: results of a multicenter study. Arch Intern Med 2003;163:181-188.

22. Saiman L, Cronquist A, Wu F, et al. An outbreak of methicillin-resistant Staphylococcus aureus in a neonatal intensive care unit. Infect Control Hosp Epidemiol 2003;24:317-321.

23. Marshall C, Harrington G, Wolfe R, Fairley CK, Wesselingh S, Spelman D. Acquisition of methicillin-resistant Staphylococcus aureus in a large intensive care unit. Infect Control Hosp Epidemiol 2003;24:322-326.

24. Muto CA, Jernigan JA, Ostrowsky BE, et al. Guideline for preventing nosocomial transmission of multidrug-resistant strains of Staphylococcus aureus and Enterococcus. Infect Control Hosp Epidemiol 2003;24:362-386.

25. Mulligan ME, Murray-Leisure KA, Ribner BS, et al. Methicillin-resistant Staphylococcus aureus: a consensus review of the microbiology, pathogenesis, and epidemiology with implications for prevention and management. Am J Med 1993;94:313-328.

26. Mermel LA, Farr BM, Sherertz RJ, et al. Guidelines for the management of intravascular catheter and device-related infections. Infect Control Hosp Epidemiol 2001;22:222-242.

27. Boyce JM, Pittet D. Guideline for hand hygiene in health-care settings: recommendations of the Healthcare Infection Control Practices Advisory Committee and the HICPAC/SHEA/APIC/IDSA Hand Hygiene Task Force. Infect Control Hosp Epidemiol 2002;23(suppl):S340.

28. Harbarth S. Handwashing: the Semmelweis lesson misunderstood? Clin Infect Dis 2000;30:990-991.

29. Hartstein AI, Le Monte AM, Iwamoto PK. DNA typing and control of methicillin-resistant Staphylococcus aureus at two affiliated hospitals. Infect Control Hosp Epidemiol 1997;18:42-48.

30. PHIS. The first year of the Department of Health's mandatory MRSA bacteraemia surveillance scheme in acute NHS Trusts in England: April 2001-March 2002. CDR Wkly 2002;12:1-17.

31. Chaix C, Durand-Zaleski I, Alberti C, Brun-Buisson C. Control of endemic methicillin-resistant Staphylococcus aureus: a cost-benefit analysis in an intensive care unit. JAMA 1999;282:1745-1751.

32. Papia G, Louie M, Tralla A, Johnson C, Collins V, Simor AE. Screening high-risk patients for methicillin-resistant Staphylococcus aureus on admission to the hospital: is it cost effective? Infect Control Hosp Epidemiol 1999;20:473-477. 